EXTENDED REPORT

\title{
Anti-Clq antibodies in nephritis: correlation between titres and renal disease activity and positive predictive value in systemic lupus erythematosus
}

\author{
N Marto, M L Bertolaccini, E Calabuig, G R V Hughes, M A Khamashta
}

Ann Rheum Dis 2005;64:444-448. doi: 10.1136/ard.2004.024943

See end of article for authors' affiliations

Correspondence to: Dr Munther A Khamashta, Lupus Research Unit, The Rayne Institute, St Thomas' Hospital, London SEl 7EH, UK; munther.khamashta@ kcl.ac.uk

Accepted 17 July 2004 Published Online First 29 July 2004

\begin{abstract}
Objective: To investigate antibodies to complement $1 \mathrm{q}$ (anti-Clq) and investigate the correlation between anti-Clq titres and renal disease in systemic lupus erythematosus (SLE).

Methods: 151 SLE patients were studied. In patients with biopsy proven lupus nephritis $(n=77)$, activity of renal disease was categorised according to the BILAG renal score. Sera were tested for anti-Clq by enzyme immunoassay. Serum samples were randomly selected from 83 SLE patients who had no history of renal disease, and the positive and negative predictive value of the antibodies was studied.

Results: Patients with active lupus nephritis (BILAG A or B) had a higher prevalence of anti-Clq than those with no renal disease $(74 \% \vee 32 \%$; relative risk $(R R)=2.3(95 \%$ confidence interval, 1.6 to 3.3$)$ ) $(p<0.0001)$. There was no significant difference in anti-Clq prevalence between SLE without nephritis and SLE with non-active nephritis (BILAG C or D) $(32 \% v 53 \%, p=0.06)$ or between active and non-active nephritis $(74 \%$ v 53\%, $p=0.06)$. Patients with nephritis had higher anti-Clq levels than those without nephritis (36.0 U/ml (range 4.9 to 401.0$)$ v $7.3 \mathrm{U} / \mathrm{ml}(4.9$ to 401.0$)$ ) ( $<<0.001)$. Anti-Clq were found in 33 of 83 patients $(39 \%)$ without history of renal disease. Nine of the 33 patients with anti-Clq developed lupus nephritis. The median renal disease-free interval was nine months. One patient with positive anti$\mathrm{Clq}$ was diagnosed as having hypocomplementaemic urticarial vasculitis syndrome during follow up. Conclusions: Anti-Clq in SLE are associated with renal involvement. Monitoring anti-Clq and their titres in SLE patients could be important for predicting renal flares.
\end{abstract}

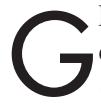
lomerulonephritis is a major determinant of the course and prognosis of systemic lupus erythematosus (SLE) and is clinically evident in $40-85 \%$ of patients. Several autoantibodies, especially those against double stranded DNA (anti-dsDNA), are believed to play a major role in the induction of glomerular inflammation. ${ }^{1-3}$ Raised titres of anti-dsDNA and hypocomplementaemia are reported to be associated with the activity of the disease. ${ }^{4-6}$ However, the lack of specificity of these biological markers for renal exacerbations has led to the search for other autoantibodies that might contribute to nephritis and help diagnose a renal flare. Recently, it has been suggested that antinucleosome antibodies are a more sensitive marker of SLE than antidsDNA, ${ }^{78}$ particularly the IgG3 isotype which might constitute a selective biological marker of active SLE and lupus nephritis. ${ }^{9}$

$\mathrm{Clq}$ is the first component of the classical pathway of complement activation and its main function is to clear immune complexes from tissues and self antigens generated during apoptosis. ${ }^{10}{ }^{11}$ Hereditary deficiency of this component is a known risk factor for the development of SLE. ${ }^{12}$ In 1984, antibodies directed to $\mathrm{Clq}$ (anti-Clq) were reported in the serum of patients with SLE, with a prevalence ranging from $34 \%$ to $47 \%{ }^{13-19}$ and in patients with hypocomplementaemic urticarial vasculitis syndrome (HUVS) with a prevalence of $100 \% .^{17}$

Recently, it has been suggested that the presence of anti$\mathrm{Clq}$ is a required condition for the development of lupus nephritis. ${ }^{2021}$ Some investigators have also proposed that monitoring anti-Clq might be valuable for the clinical management of SLE patients as a non-invasive biological marker of renal disease. ${ }^{22}$ However, to date, testing for these antibodies still does not have a definite place in daily clinical practice.
We designed this study to investigate further the clinical value of anti-Clq in a large cohort of SLE patients.

\section{METHODS}

\section{Patients}

The first part of this study comprised 151 patients with SLE, all fulfilling the 1982 criteria for the classification of the disease $^{23}$ ( 141 female, 10 male; median age 39 years (range 15 to 74$)$; median disease duration 8 years (0.1 to 52$)$ ). Seventy seven patients had biopsy proven lupus nephritis and 74 had no evidence of renal disease at the time of the study.

For the second part of the study, we included 83 consecutive patients fulfilling at least four of the 1982 criteria for the classification of $\operatorname{SLE}^{23}$ (78 female, 5 male; median age 44 years (18 to 74 ); median disease duration 9 years ( 1 to 52), median follow up 24 months ( 1 to 60)) with no previous history of renal involvement at the time of serum collection. All medical records were carefully reviewed retrospectively.

\section{Procedures}

Evaluation of renal involvement

The World Health Organisation (WHO) classification of lupus nephritis ${ }^{24}$ was used to define the histological lesions, and mixed forms were classified in keeping with the identified proliferative lesion. The individual components of the renal pathology were classified and scored according to previously published activity and chronicity scores. ${ }^{25}$

Data on renal disease activity corresponding to the patients' samples were abstracted from medical records and

Abbreviations: anti-dsDNA, antibodies against double stranded DNA; APS, antiphospholipid syndrome; BILAG, British Isles Lupus Assessment Group; SLE, systemic lupus erythematosus 


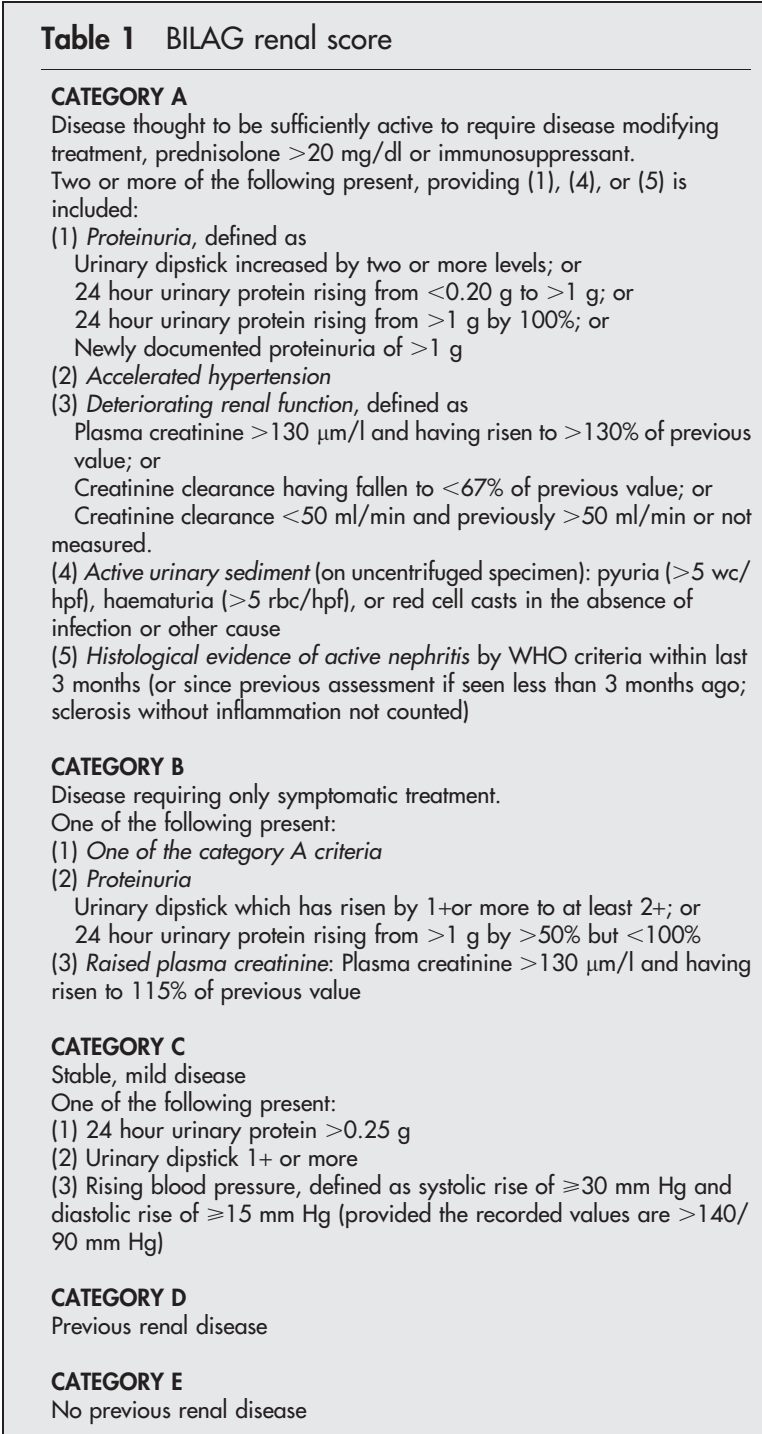

BILAG, British Isles Lupus Assessment Group; HPF, high power field; rbc, red blood cell; wc, white cell.

categorised according to the British Isles Lupus Assessment Group (BILAG) renal score. ${ }^{26}$ The BILAG index assesses eight organs or systems separately, and each system is allocated an alphabetic score (A-E) defined by the presence or absence of specific clinical features (table 1 ).

In the majority of patients with nephritis, serum samples were taken before starting immunosuppressive treatment. However, as some patients were treated locally, their blood was tested in the first four months after the beginning of the immunosuppressive treatment.

\section{Anti-Clq determination}

Anti-Clq were tested in serum using a commercially available enzyme immunoassay (EIA) kit (Diagenics, Milton Keynes, UK), under $1 \mathrm{M} \mathrm{NaCl}$ conditions as described previously. ${ }^{27}$ Briefly, standards, controls, and patient sera were incubated with human $\mathrm{Clq}$ adsorbed into the microtitre plate. After washing, an IgG horseradish peroxidase labelled conjugate was added in the appropriate dilution. Colour was developed by adding an enzyme substrate (tetramethylbenzidine in citrate buffer with hydrogen peroxidase). The reaction was stopped by adding $0.25 \mathrm{M}$ sulphuric acid and optical densities at $450 \mathrm{~nm}$ were measured by a Titertek Multiskan MC apparatus (Flow Laboratories, Herts, UK). Optical densities

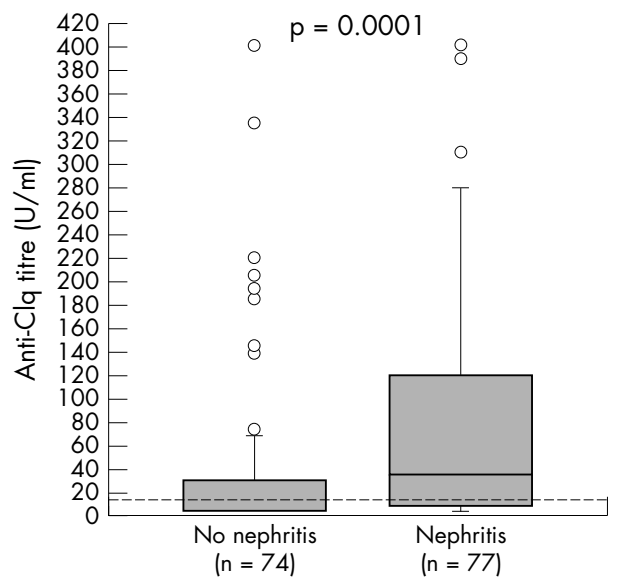

Figure 1 Anti-Clg antibody titres in 151 patients with systemic lupus erythematosus. Dashed lines indicate cut off for positivity. This graph shows the median, first to third quartiles (box), interquartile range (whiskers), and outliers (circles). Higher titres of anti-Clq were found in patients with $v$ without renal involvement; the difference was significant.

were then converted to units ( $\mathrm{U}$ ) by being plotted against the autoantibody titre of the standards given by the manufacturer.

\section{Other laboratory measurements}

Levels of serum complement C3 and C4 were measured by nephelometry, and anti-dsDNA by radioimmunoassay.

\section{Statistical analysis}

All statistical analysis was carried out using the SPSS 11.0 program (Microsoft software). Comparisons between patients groups were expressed as relative risk with $95 \%$ confidence interval (RR $(95 \% \mathrm{CI})$ ), where only a lower limit $>$ l was considered significant. Differences between means were analysed by the Spearman correlation coefficient. Comparisons between subject groups were made using Mann-Whitney test. A probability ( $p$ ) value of $<0.05$ was considered significant.

\section{RESULTS}

\section{Demographic data and clinical characteristics}

The nephritis group $(n=77)$ comprised six male and 71 female patients, with a median age of 35 years (range

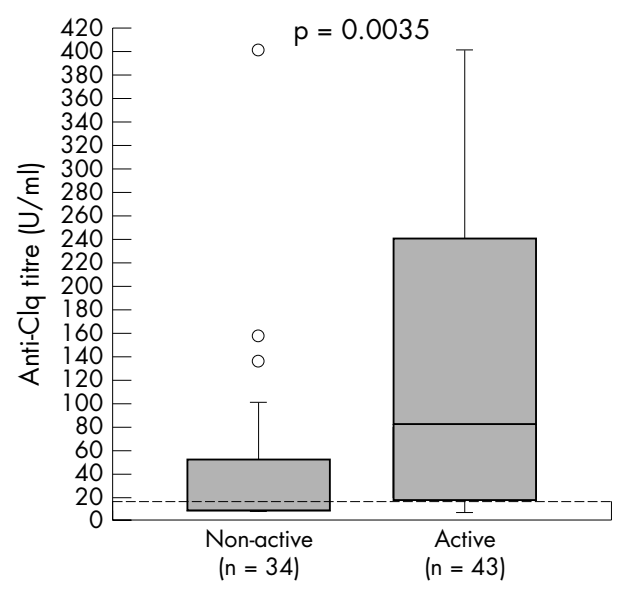

Figure 2 Anti-Clq titres and activity of renal disease in 77 patients with systemic lupus erythematosus and renal involvement. This graph shows the median, first and third quartiles (box), interquartile range (whiskers), and outliers (circles). Higher titres of anti-Clq were found in patients with $v$ without renal involvement; the difference was significant. 
15 to 65$)$ and a median disease duration of eight years (0.1 to 36$)$.

Fifty five patients had proliferative nephritis (26 in class III and 29 in class IV), 10 had membranous nephritis (class V), 11 had mesangial nephritis (class II), and one had glomerulosclerosis according to the WHO classification. At the time of the sera collection, 43 patients were categorised as having active nephritis (39 in BILAG category A and four in category B). Thirty four patients had quiescent renal disease (26 in BILAG category $\mathrm{C}$ and eight in category $\mathrm{D}$ ). Twenty one of these patients fulfilled criteria for the antiphospholipid syndrome (APS). ${ }^{28}$

The non-nephritis group $(\mathrm{n}=74)$ comprised four male and 70 female patients, with a median age of 44 years ( 18 to 74 ) and a median disease duration of nine years ( 1 to 52). Fifteen of these patients fulfilled criteria for the APS. ${ }^{28}$

There were no differences in male/female distribution or disease duration between groups. However, patients with nephritis were younger than the non-nephritis group $(\mathrm{p}=0.0001)$.

\section{Prevalence and clinical associations of anti-C lq}

Anti-Clq were found in 74 of the 151 SLE patients (49\%). Patients with nephritis more often had anti-Clq than those without a history of renal disease $(65 \% v 32 \%$, RR $=2.0(95 \%$ CI, 1.4 to 2.9); $\mathrm{p}<0.001$ ). Patients with active lupus nephritis (BILAG A or B) had a higher prevalence of anti-Clq than those without renal disease $(74 \% v 32 \%, \mathrm{RR}=2.3$ ( 1.6 to 3.3$)$; $\mathrm{p}<0.0001)$. However, there was no significant difference between patients without nephritis and those with nonactive nephritis (BILAG C or D) $(32 \% v 53 \%$; $=0.06)$ or between patients with active and non-active nephritis $(74 \% \mathrm{v}$ $53 \% ; \mathrm{p}=0.06$ ).

Higher titres of anti-Clq were found in patients with renal involvement than in those with no renal involvement $(36.0 \mathrm{U} / \mathrm{ml} \quad(4.9$ to 401.0$) \quad v \quad 7.3 \mathrm{U} / \mathrm{ml} \quad(4.9$ to 401.0$))$ $(\mathrm{p}<0.001)$ (fig 1$)$. In particular, those with active nephritis had significantly higher anti-Clq titres than those with quiescent renal involvement $(80.0 \mathrm{U} / \mathrm{ml}(4.9$ to 401.0$) v$ $17.5 \mathrm{U} / \mathrm{ml}(4.9$ to 401.0$))(\mathrm{p}=0.0035)$ (fig 2$)$.

There were no differences in anti-Clq prevalence or titres between patients with proliferative and non-proliferative glomerulopathy $(69 \% v 57 \%$, or $34.5 \mathrm{U} / \mathrm{ml}$ (4.9 to 401.0$) v$ $40.9 \mathrm{U} / \mathrm{ml}$ (4.9 to 401.0$)$, respectively.

\section{Anti-Clq and other serological markers of disease activity}

When comparing anti-Clq titres with known serological markers of disease activity, we found a negative correlation with levels of $\mathrm{C} 3$ and $\mathrm{C} 4$ and a positive correlation with

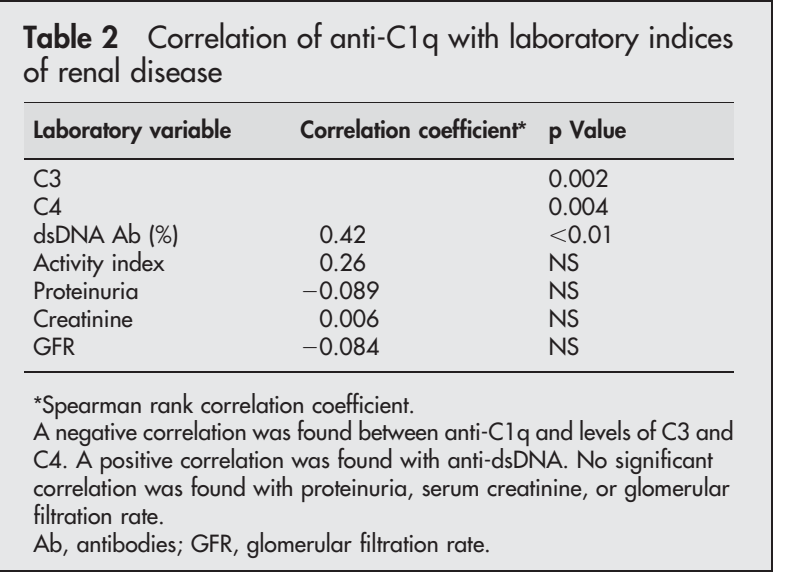

anti-dsDNA. No significant correlation was found with serum creatinine, glomerular filtration rate, proteinuria, or histological activity index (table 2 ).

\section{Anti-Clq in patients with no renal disease}

As some patients without nephritis had positive anti-Clq, we studied a cohort of 83 SLE patients with no previous history of renal involvement at the time of serum collection.

Anti-Clq were detected in 33 of the 83 patients (39.8\%). Nine of these 33 patients (27.3\%) developed lupus nephritis. All nine patients underwent renal biopsy which showed a proliferative form of glomerulopathy (WHO classes III or IV). The renal disease-free interval from the time of serum collection ranged from two to 48 months (median nine months). One patient with positive anti-Clq was later diagnosed as having hypocomplementaemic urticarial vasculitis syndrome (HUVS).

The remaining 23 patients with positive anti-Clq are being closely followed up for the development of kidney disease.

None of the 50 patients with negative anti-Clq developed any sign of renal involvement.

\section{DISCUSSION}

Our studies were designed to clarify the role of anti-Clq testing in the diagnosis and monitoring of SLE. In a cross sectional study of a cohort of 151 SLE outpatients, 77 with and 74 without lupus nephritis, we showed a strong association between high titres of anti-Clq and renal disease, especially active glomerulonephritis. In addition, in a retrospective analysis of 83 SLE patients, anti-Clq were found to have very high sensitivity and negative predictive value for the occurrence of renal disease.

Anti-Clq were detected in $65 \%$ of patients with nephritis, compared with $32 \%$ of those with no renal disease-a prevalence within the range reported in previous studies. ${ }^{15} 181929{ }^{30}$ Specifically, higher titres were associated with the presence of nephritis, as previously described. ${ }^{15}{ }^{19}{ }^{31}$ Our data confirm a strong association between anti-Clq and lupus nephritis in a large series of patients, including a significant number with nephritis.

Earlier investigations suggested that development or recurrence of nephritis was associated with rising titres of anti-Clq in the preceding six months ${ }^{19}{ }^{31}$ and that these were more specific for active renal involvement than anti-dsDNA. ${ }^{32}$ This prompted us to explore the potential role of anti-Clq in the early diagnosis of renal relapses. Comparing patients with active and inactive nephritis, defined according to strict criteria, we showed that although there was no significant difference in the prevalence of anti-Clq, active nephritis was associated with higher titres.

Like others, 152931 we found a good correlation between anti-Clq and other recognised markers of disease activity in SLE. Curiously, although higher anti-dsDNA values were associated with activity of nephritis, there was no difference in prevalence of anti-dsDNA in patients with and without nephritis, supporting previous evidence of the superior specificity of anti-Clq over anti-dsDNA for renal flares. ${ }^{31}{ }^{32}$ It is clear that these findings could have been influenced by the fact that some of the serum samples were taken in the first four months after beginning immunosuppressive treatment, as anti-dsDNA values fall very rapidly after treatment. $^{33}$

In our retrospective study, 33 of 83 patients had anti-Clq at the time of serum sampling. Increased levels of anti-Clq were found in all the nine patients who developed renal disease during follow up. The positive predictive value of anti-Clq for nephritis was $9 / 33(27.3 \%)$, which is lower than in other reports, ${ }^{19} 20$ probably because our follow up period was shorter. More significantly, none of the 50 patients negative 
for anti-Clq had or developed lupus nephritis, corresponding to a negative predictive value of $100 \%$. Again, our results corroborate findings from smaller studies and strengthen the hypothesis that there is no lupus nephritis in the absence of anti-Clq. ${ }^{21}$

However, we must bear in mind that in our cross sectional study only $65 \%$ of patients with renal disease had anti-Clq, implying that $35 \%$ of patients with nephritis, and in particular $26 \%$ with active nephritis, tested negative for antibodies to Clq. We could not single out a different characteristic in these patients, even in the histological type of lesion on renal biopsy. However, three of these patients were tested for anti-Clq while on treatment for nephritis. In addition, patients with nephritis and negative anti-Clq titres tended to have more longstanding disease, particularly renal disease (data not shown), so we might speculate that they were heavily immunosuppressed in the past. This could be a reason for false negative testing, as earlier reports show a decline in anti-Clq following initiation of immunotherapy. ${ }^{30}{ }^{34}$ Other possible explanations for the absence of antiClq in some patients with active lupus nephritis are raised by studies by Gunnarsson et al. ${ }^{18}$ In a longitudinal study of 21 SLE patients with active disease, they found that all patients with proliferative nephritis had high ongoing production of anti-Clq in peripheral cells, although not every one had positive serum levels of anti-Clq. ${ }^{18}$ The same investigators reported that only 11 of 18 patients with biopsy confirmed lupus nephritis had anti-Clq but Clq was low in most of these patients and correlated negatively with anti-Clq. A question is raised as to whether the antibodies bind to Clq, forming immune complexes, or are particularly readily sequestered in the kidney. ${ }^{35}$

One of the important physiological functions of the classical pathway of complement is the disposal of immune complexes and the products of inflammatory injury, and recent data suggest a role for $\mathrm{Clq}$ in the clearance of apoptotic cells. ${ }^{10}{ }^{11}$ There is at present much interest in the hypothesis that a major source of the autoantigens driving the immune response in SLE is the apoptotic cell. Binding of autoantibodies to the collagen-like region of $\mathrm{Clq}$ could interfere with activation of $\mathrm{Cl}$ and functionally resemble a Clq deficient state. This may provide a unifying explanation for the paradoxical finding that homozygous Clq deficiency causes SLE while many patients with SLE have anti-Clq. In both situations the interference with the putative physiological role of Clq mediated clearance of apoptotic cells would result in autoimmunity. ${ }^{36}$

The strong correlation between anti-Clq and lupus nephritis appears to be a general finding in our own and many other studies. Anti-Clq show a significant inverse correlation with levels of Clq, C3, and C4 1519293537 and decreases in these components of the complement classical pathway are associated with active renal disease. ${ }^{35} 38$ In addition, anti-Clq have been recovered at necropsy from the glomeruli of patients with proliferative lupus nephritis. ${ }^{40} \mathrm{~A}$ recent experimental report in rodents showed that infusion of anti-Clq resulted in reduced levels of circulating $\mathrm{Clq}$ and deposition of anti-Clq and complement components in the glomerulus. ${ }^{41}$ The available data suggest that autoantibodies against $\mathrm{Clq}$ have a definite role in the pathogenesis of lupus glomerular injury but so far we can only speculate how these antibodies exert their nephritogenic effect. Anti-Clq may either contribute to the formation of circulating immune complexes that are deposited in the kidneys or contribute to local formation of immune complexes on the glomerular basement membrane. By interfering with activation of the complement system through the classical pathway, anti-Clq may hamper immune complex solubilisation, further contributing to immune complex deposition in the kidney.
Prevailing knowledge associates anti-Clq specifically with proliferative forms of lupus nephritis. ${ }^{14} 15181931$ However, we did not find differences in the prevalence or levels of anti-Clq when comparing proliferative and non-proliferative forms of nephritis. We suggest that previous results, drawn from a small number of patients-particularly those with nonproliferative nephritis-do not hold true in a large patient cohort. This implies that, contrary to the accepted wisdom, anti-Clq have a potential pathogenic effect in all types of lupus nephritis, including mesangial and membranous nephritis.

\section{Conclusions}

In a representative sample of the population in a lupus clinic, we have shown that anti-Clq are useful to identify a subgroup of SLE patients at risk for renal disease, and that monitoring anti-Clq titres is potentially more helpful in the early diagnosis of nephritis or the prediction of renal flares than the currently employed indices of disease activity.

\section{Authors' affiliations}

N Marto, M L Bertolaccini, E Calabuig, G R V Hughes, M A Khamashta, Lupus Research Unit, The Rayne Institute, St Thomas' Hospital, London, UK

\section{REFERENCES}

1 Lefkowith JB, Gilkeson GS. Nephritogenic autoantibodies in lupus: current concepts and continuing controversies. Arthritis Rheum 1996;39:894-903.

2 Berden JH. Lupus nephritis. Kidney Int 1997;52:538-58.

3 Hahn BH. Antibodies to DNA. N Engl J Med 1998;338:1359-68.

4 Isenberg DA, Ravirajan CT, Rahman A, Kalsi J. The role of antibodies to DNA in systemic lupus erythematosus - a review and introduction to an international workshop on DNA antibodies held in London, May 1996. Lupus 1997; 6:290-304

5 Lloyd W, Schur PH. Immune complexes, complement, and anti-DNA in exacerbations of systemic lupus erythematosus (SLE). Medicine (Baltimore) $1981 ; 60: 208-17$.

6 Swaak AJ, Aarden LA, Statius van Eps LW, Feltkamp TE. Anti-dsDNA and complement profiles as prognostic guides in systemic lupus erythematosus. Arthritis Rheum 1979;22:226-35.

7 Bruns A, Blass S, Hausdorf G, Burmester GR, Hiepe F. Nucleosomes are major $T$ and $B$ cell autoantigens in systemic lupus erythematosus. Arthritis Rheum 2000;43:2307-15.

8 Amoura Z, Koutouzov S, Piette JC. The role of nucleosomes in lupus. Curr Opin Rheumatol 2000;12:369-73.

9 Amoura Z, Koutouzov S, Chabre H, Cacoub P, Amoura I, Musset L, et al. Presence of antinucleosome autoantibodies in a restricted set of connective tissue diseases: antinucleosome antibodies of the $\lg G 3$ subclass are markers of renal pathogenicity in systemic lupus erythematosus. Arthritis Rheum 2000;43:76-84.

10 Walport MJ. Complement. Part 1. N Engl J Med 2001;344:1058-66.

11 Walport MJ. Complement. Part 2. N Engl J Med 2001;344:1140-4.

12 Bowness P, Davies KA, Norsworthy PJ, Athanassiou P, Taylor-Wiedeman J, Borysiewicz $\mathrm{LK}$, et al. Hereditary $\mathrm{Clq}$ deficiency and systemic lupus erythematosus. Q J Med 1994;87:455-64.

13 Uwatoko S, Aotsuka S, Okawa M, Egusa Y, Yokohari R, Aizawa C, et al. Characterization of $\mathrm{Clq}$-binding $\mathrm{lgG}$ complexes in systemic lupus erythematosus. Clin Immunol Immunopathol 1984;30:104-16.

14 Wener MH, Uwatoko S, Mannik M. Antibodies to the collagen-like region of $\mathrm{Clq}$ in sera of patients with autoimmune rheumatic diseases. Arthritis Rheum 1989;32:544-51

15 Siegert C, Daha M, Westedt ML, van der Voort E, Breedveld F. IgG autoantibodies against $\mathrm{Clq}$ are correlated with nephritis, hypocomplementemia, and dsDNA antibodies in systemic lupus erythematosus. J Rheumatol 1991;18:230-4.

16 Siegert CE, Daha MR, Halma C, van der Voort EA, Breedveld FC. IgG and IgA autoantibodies to $\mathrm{Clq}$ in systemic and renal diseases. Clin Exp Rheumatol 1992;10:19-23.

17 Wisnieski JJ, Jones SM. IgG autoantibody to the collagen-like region of Clq in hypocomplementemic urticarial vasculitis syndrome, systemic lupus erythematosus, and 6 other musculoskeletal or rheumatic diseases. J Rheumatol 1992;19:884-8.

18 Gunnarsson I, Ronnelid J, Huang YH, Rogberg S, Nilsson B, Lundberg I, et al. Association between ongoing anti-Clq antibody production in peripheral blood and proliferative nephritis in patients with active systemic lupus erythematosus. Br J Rheumatol 1997;36:32-7.

19 Siegert CE, Daha MR, Tseng CM, Coremans IE, van Es LA, Breedveld FC. Predictive value of $\lg G$ autoantibodies against $\mathrm{Clq}$ for nephritis in systemic lupus erythematosus. Ann Rheum Dis 1993;52:851-6. 
20 Trendelenburg M, Marfurt J, Gerber I, Tyndall A, Schifferli JA. Lack of occurrence of severe lupus nephritis among anti-Clq autoantibody-negative patients. Arthritis Rheum 1999;42:187-8.

21 Fremeaux-Bacchi V, Noel LH, Schifferli JA. No lupus nephritis in the absence of antiClq autoantibodies? Nephrol Dial Transplant 2002;17:2041-3.

22 Siegert CE, Kazatchkine MD, Sjoholm A, Wurzner R, Loos M, Daha MR. Autoantibodies against $C l q$ : view on clinical relevance and pathogenic role. Clin Exp Immunol 1999;1 16:4-8.

23 Tan EM, Cohen AS, Fries JF, Masi AT, McShane DJ, Rothfield NF, et al. The 1982 revised criteria for the classification of systemic lupus erythematosus. Arthritis Rheum 1982;25:1271-7.

24 Churg J, Bernstein J, Glassock RJ. Renal disease: classification and atlas of glomerular diseases. New York: Igaku-Shoin 1995.

25 Austin HA, Muenz LR, Joyce KM, Antonovych TT, Balow JE. Diffuse proliferative lupus nephritis: identification of specific pathologic features affecting renal outcome. Kidney Int 1984;25:689-95.

26 Hay EM, Bacon PA, Gordon C, Isenberg DA, Maddison P, Snaith ML, et al The BILAG index: a reliable and valid instrument for measuring clinical disease activity in systemic lupus erythematosus. Q J Med 1993;86:447-58.

27 Coremans IE, Daha MR, van der Voort EA, Muizert Y, Halma C, Breedveld FC. Antibodies against $\mathrm{Clq}$ in anti-glomerular basement membrane nephritis. Clin Exp Immunol 1992:87:256-60.

28 Wilson WA, Gharavi AE, Koike T, Lockshin MD, Branch DW, Piette JC, et al. International consensus statement on preliminary classification criteria for definite antiphospholipid syndrome: report of an international workshop. Arthritis Rheum 1999;42:1309-11.

29 Horvath L, Czirjak L, Fekete B, Jakab L, Pozsonyi T, Kalabay L, et al. High levels of antibodies against $\mathrm{Clq}$ are associated with disease activity and nephritis but not with other organ manifestations in SLE patients. Clin Exp Rheumatol 2001;19:667-72.

30 Haseley LA, Wisnieski JJ, Denburg MR, Michael-Grossman AR, Ginzler EM Gourley MF, et al. Antibodies to $\mathrm{Clq}$ in systemic lupus erythematosus: characteristics and relation to Fc gamma RllA alleles. Kidney Int 1997;52:1375-80.
31 Coremans IE, Spronk PE, Bootsma H, Daha MR, van der Voort EA, Kater L, et al. Changes in antibodies to $\mathrm{Clq}$ predict renal relapses in systemic lupus erythematosus. Am J Kidney Dis 1995;26:595-601.

32 Moroni G, Trendelenburg M, Del Papa N, Quaglini S, Raschi E, Panzeri P et al. Anti-Clq antibodies may help in diagnosing a renal flare in lupus nephritis. Am J Kidney Dis 2001;37:490-8.

33 Egner W. The use of laboratory tests in the diagnosis of SLE. J Clin Pathol 2000:53:424-32.

34 Ronnelid J, Huang YH, Norrlander T, Rogberg S, Nilsson B, Gustafsson R, et al. Short-term kinetics of the humoral anti-Clq response in SLE using the ELISPOT method: fast decline in production in response to steroids. Scand J Immunol 1994;40:243-50.

35 Gunnarsson I, Sundelin B, Heimburger M, Forslid J, van Vollenhoven R, Lundberg I, et al. Repeated renal biopsy in proliferative lupus nephritis predictive role of serum Clq and albuminuria. J Rheumatol predictive role of

36 Pickering MC, Walport MJ. Links between complement abnormalities and systemic lupus erythematosus. Rheumatology (Oxford) 2000;39:133-41.

37 Fremeaux-Bacchi V, Weiss L, Demouchy C, Blouin J, Kazatchkine MD. Autoantibodies to the collagen-like region of $\mathrm{Cl} q$ are strongly associated with classical pathway-mediated hypocomplementemia in systemic lupus erythematosus. Lupus 1996;5:216-20.

38 Jonsson H, Sturfelt G, Martensson U, Truedsson L, Sjoholm AG. Prospective analysis of $\mathrm{Cl}$ dissociation and complement activation in patients with systemic lupus erythematosus. Clin Exp Rheumatol 1995; 13:573-80.

39 Swaak AJ, Groenwold J, Bronsveld W. Predictive value of complement profiles and anti-dsDNA in systemic lupus erythematosus. Ann Rheum Dis 1986:45:359-66.

40 Mannik M, Wener MH. Deposition of antibodies to the collagen-like region of $\mathrm{Clg}$ in renal glomeruli of patients with proliferative lupus glomerulonephritis. Arthritis Rheum 1997;40:1504-11.

41 Trouw LA, Seelen MA, Duijs JM, Benediktsson H, Van Kooten C, Daha MR. Glomerular deposition of $\mathrm{Clq}$ and anti-Clq antibodies in mice following injection of antimouse Clq antibodies. Clin Exp Immunol 2003;132:32-9. 